
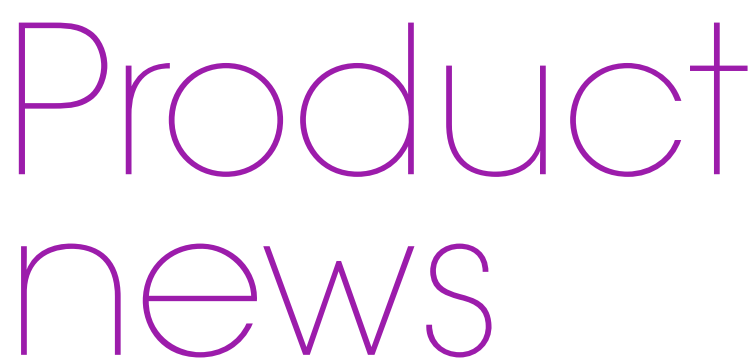

\section{INSIDER KNOWLEDGE TO EXCEL IN SOCIAL MEDIA}

Dental marketing expert Shaz Memon, creative director of Digimax and Digimax Dental, has written Instagram for dentists, sharing insider marketing knowledge and influencer secrets designed to power practice growth.

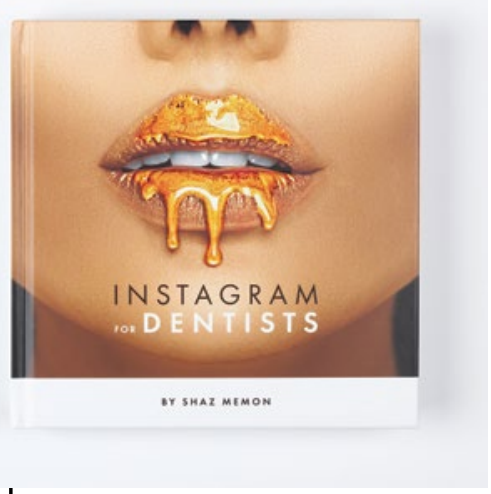

Shaz wanted to show anyone within dentistry that Instagram is easy to master and a lot of fun, too. With this book, dental professionals can learn to use Instagram to grow a brand effectively, creatively and confidently.
The easy-to-reference book covers a range of essential topics, including:

- Which Instagram account to have

- How to brand an account

- How to be interesting

- How to identify your voice

- How to attract new patients

- How to grow followers authentically

- How to hashtag

- How to use the 'influencer' approach

- How to use Instagram stories

- How to use IGTV

- How to create the right images

- What and when to post - and much, much more.

Specifically tailored to dental professionals, Instagram for dentists is a definitive guide designed in an easy-tofollow reference format with bite-size chapters to make learning easier.

All profits go to the charity Wells on Wheels.

Instagram for dentists can be ordered from Amazon.

\title{
ENHANCED CPD FOR ALL
}

The British Dental Conference and Dentistry Show offers hours of enhanced CPD designed for the entire dental team. Lecture programmes are dedicated to each role in the profession and sessions are led by nationally and internationally renowned speakers.

Further still, the trade floor will host more than 450 manufacturers and suppliers, with many providing on-stand learning opportunities as well as exclusive promotions and live demonstrations.

All this makes the event the perfect place
MOTIVATIONAL APP HITS 400,000
DOWNLOADS

The free Brush DJ app, which uses music to engage and motivate users to have an effective oral hygiene routine, has kicked off 2020 by receiving its 400,000th download. The app has also reached people in 204 countries and remains the only dental app in the NHS App Library.

Unfortunately, basic oral hygiene messages are not reaching, or being acted on by everyone in the population. The Brush DJ app is a low-cost part of the solution and can be used with any toothbrush. This makes it sustainable and helps to reduce inequalities.

Founder and CEO of Brush DJ Ltd Ben Underwood, who is also a dentist, said that hitting 400,000 downloads was a fantastic milestone that would not have been possible without all the people who have helped build, test and champion the app.

Following SBRI Healthcare funding in 2019 the Brush DJ team have investigated the feasibility, opportunity for commercialisation and end user acceptance of enhancing the established Brush DJ app, by evaluating several potential new features. Patient, carer and stakeholder feedback was gained to determine the three most desired, technically feasible and commercially viable features. The team are now raising funding to build the enhanced version and help more people around the world to have a healthy smile.

http://www.brushdj.com/ to bring the whole team. Make sure you don't miss out for 2020 !

The British Dental Conference and Dentistry Show 2020 - 15 and 16 May Birmingham NEC, co-located with DTS.

For all the latest information, please visit www.thedentistryshow.co.uk, call 0207348 5270 or email dentistry@closerstillmedia. com.

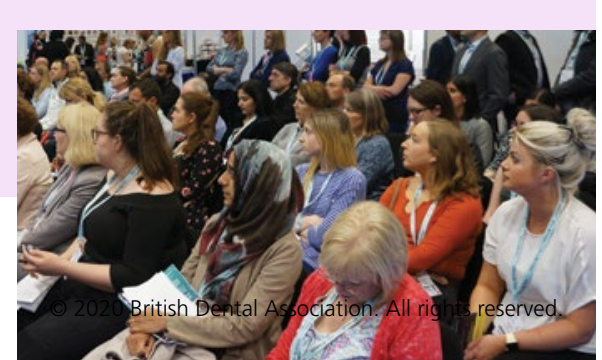

If you would like to promote your products or services direct to the dental industry in BDJ Team, call Andy May on 020 78434785 or email a.may@nature. com. 